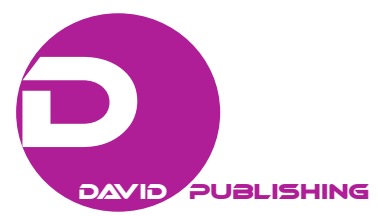

\title{
Categorization of Meta-Cognition and Its Implication for Competence Building: An Empirical Research in
}

\section{Language Economics*}

\author{
Yin Xue-yan \\ Guangdong University of Foreign Studies, Guangzhou, China
}

\begin{abstract}
Language in nature is a very important human capital endowed by language learners, characterized by economic attributes of "value”, "utility”, and "cost”, manifesting itself in the individual’s language use ability. Since little literature has drawn attention to meta-cognition of business English (BE) learners, through questionnaire-based quantitative research and qualitative categorization, this paper constructs a meta-cognitive system of BE learners with regulatory meta-cognition as the core, and further explores the impact of meta-cognition on BE competence developing. It is found that meta-cognitive knowledge, meta-cognitive experience, and meta-cognitive regulation constitute the meta-cognitive system of BE learners. Meta-cognitive regulation lies in the category center and has a significant impact on BE competence developing. The stronger the meta-cognitive knowledge and regulation are, the stronger BE competence would be. Meta-cognitive experience also plays an important role in BE study, despite its statistically insignificant impact on competence development. Therefore, developing meta-cognition, especially meta-cognitive regulation of language learners is of great statistical significance to improve the return of human capital in BE investment.
\end{abstract}

Keywords: business English competence, meta-cognitive knowledge, meta-cognitive experience, meta-cognitive regulation

\section{Introduction}

The National Standard for Teaching Quality of Undergraduates in Colleges and Universities in China (abbreviated as "National Standard") clarifies the training specifications of business English (thereinafter referred to as BE) professionals in colleges and universities from the three core dimensions of "quality", "knowledge", and "skills". It reduces the abilities that BE professionals should possess into 21 sub-indicators (see Table 1), and distinguishes the two prominent concepts of "knowledge" and "skill” in BE teaching. The National Standard clearly addresses for the first time the core competence BE professionals should possess. Narrowly speaking, BE competence centers on training learners' ability of English use in business contexts, while in a broad sense, it emphasizes a heuristic integration of learner's "quality", "knowledge", and "skills"

\footnotetext{
* Acknowledgements: This paper is funded by Impact of Human Capitals on Investment Return of Business English Education: From the Perspective of Language Economics (No. 16-005B) and The Association Project of Comparative Study of English and Chinese in the New Era (No. 298), research projects in South China Business College, Guangdong University of Foreign Studies; English Language and Literature, a key project in Guangdong Province, China.

Yin Xue-yan, associate professor, South China Business College, Guangdong University of Foreign Studies.
} 
(The Teaching Guiding Committee for College Foreign Language Majors under the Ministry of Education, 2018).

Table 1

BEC Dimensions and Its Sub-Indicators

\begin{tabular}{|l|l|l|l|}
\hline Dimension & Quality & Knowledge & Skills \\
\hline \multirow{5}{*}{21 sub-indicators } & Ideological & $\begin{array}{l}\text { Knowledge of the English language; } \\
\text { Knowledge of business. }\end{array}$ & $\begin{array}{l}\text { Language use skills; } \\
\text { Literacy appreciation skills. }\end{array}$ \\
\cline { 2 - 4 } & Professional & $\begin{array}{l}\text { Knowledge of cross-cultural communication; } \\
\text { Knowledge of inter-discipline. }\end{array}$ & $\begin{array}{l}\text { Skills in cross-cultural } \\
\text { communications }\end{array}$ \\
\cline { 2 - 4 } & Occupational & Knowledge of Chinese language and culture. & $\begin{array}{l}\text { Critical thinking; } \\
\text { Research potential. }\end{array}$ \\
\cline { 2 - 4 } & Cultural & Knowledge of adjacent disciplines. & $\begin{array}{l}\text { Innovation ability; } \\
\text { Independent learning skills. }\end{array}$ \\
\cline { 2 - 4 } & Healthy & knowledge of humanities and social sciences. & $\begin{array}{l}\text { Information skills; } \\
\text { Practical skills. }\end{array}$ \\
\hline
\end{tabular}

As a comparatively new program launched in mainland China, BE has witnessed a historical development since 2006, when Shanghai Institute of Foreign Economics and Trade launched the first undergraduate BE major on a trial basis. However, very few literature on BE competence has been found in overseas academics. Quantitative analysis of 965 relevant literatures in CNKI China shows that the domestic research mainly focuses on the linguistic function of English in business contexts (Chen \& Ge, 2016), pragmatic competence of BE students (Q. Li \& D. Li, 2018), grammar competence (He, 2017), intercultural communication skills (Liu, 2018), and review or design of BE competence scale (Wang \& Fan, 2017).

As language economics states, language in nature is a very important human capital, characterized by economic attributes of "value”, "utility”, and "cost”, and manifests itself as the individual's language use ability. Building on theories in cognitive linguistics and language economics, we propose that BE competence, as a human capital, is not only the unity of general cognition, but also the state of more complicated meta-cognitive activities. Meta-cognitive competence and general cognitive competence may constitute two main dimensions of core competence of BE professionals (Yin \& Li, 2015).

Drawing on the value attribute of language as a human capital, the current research aims to further explore the meta-cognitive system of $\mathrm{BE}$ and its implication for competence-building of BE professionals. Competence in this context is broadly considered as the integrated combinations of "quality", "knowledge", and "skills" as denoted in the National Standard.

\section{Meta-Cognition}

American psychologist, Flavell (1976), the founder of meta-cognition, believed that meta-cognition is "cognition of cognition" and "knowledge or cognitive activity reflecting or regulating cognitive activities" (p. 232). Flavell (1979) divided meta-cognition into three dimensions: meta-cognitive knowledge, meta-cognitive experience, and meta-cognitive skills. The former includes three categories or variables: knowledge of person, knowledge of task, and knowledge of strategy. Meta-cognitive experience is an individual's judgment and experience of various experiences, while meta-cognitive skills are of great significance to cognitive activities, such as oral communication, reading comprehension, writing, language acquisition, observation, memory, and problem-solving (pp. 906-911). Brown (1987) further proposed four elements of meta-cognition, namely, planning, monitoring, evaluation, and revising. Meta-cognitive knowledge and active monitoring or regulation 
has become the focus of the research, which emphasize the individual's cognitive ability, strategy, knowledge, and the individual's ability to plan, monitor, and regulate in the cognitive process.

Much of the foreign literature stresses the "strategy" dimension of meta-cognition, while others attach great importance to the role of meta-cognition in second language acquisition. They emphasize the impact of meta-cognitive monitoring on the effective implementation of thinking activities. The factors influencing meta-cognitive strategy selection (O’Malley \& Chamot, 1990), the use of meta-cognitive strategies by advanced learners and the effects of meta-cognitive strategies on reading, listening, and speaking skills in the second language acquisition (Oxford, 2003; McKeown \& Gentilucci, 2007; Mijuskovic, 2014) have become a big concern. In recent years, the focus of foreign research has gradually shifted from conceptual meta-cognition to cognitive competency, which makes the research more operational and reliable.

Quirk (2014, pp. 223-234) systematically expounded the importance of overcoming meta-cognitive impairment to improve the meta-cognitive ability of medical workers through case analysis. Kisin (2015, pp. 27-34) used strategy inventory for language learning (SILL) scale to investigate the meta-cognitive status of sophomores majoring in BE in a Serbian university, and explored the statistical relationship between meta-cognitive ability and BE learning through qualitative and quantitative research. Stanciu et al. (2011, pp. 1914-1923) investigated the development of meta-cognitive ability of 239 freshmen in three Romanian universities, and found that the development of students' meta-cognitive ability was significantly related to gender, middle schooling, and region. Zhao (2016, pp. 68-78) conducted a 12-week meta-cognitive experiment on 102 freshmen of a university in China, pointing out the statistical significance of meta-cognitive strategies, such as computer-supported collaborative inquiry learning (CSCIL) in improving students' language proficiency.

The deepening interest in carrying out cognition research in China was exemplified in the coverage of meta-cognitive factors or implications in Nie and Xu (2001), Confucius and Li (2008), and Wang (2012); meta-cognitive awareness or cultivation in second language acquisition in Zhang (2009), Shi (2012), Xu (2013), and Zhang, Feng, Fu, and Wang (2013, p. 4); meta-cognitive strategy in Lu (2006), Chang and Li ( 2009), Shao and Zhao (2011), Chang and Yu (2014), and Wang (2014). Meta-cognitive knowledge (Ji, 2005), meta-cognitive experience ( $\mathrm{Wu}, 2006)$, and meta-cognitive monitoring (Chen \& Wen, 2010; Huang, 2012; Mu \& Chen, 2013) have become more prominently addressed on qualitative research level.

Since earlier literature barely saw the meta-cognitive issues in BE, we are thus aiming to explore the meta-cognitive system of $\mathrm{BE}$ and its economic value for competence-building, drawing on theoretical frameworks in cognitive linguistics and linguistic economics. Considering little quantitative evidence has been given, the current research would quantitatively focus on two critical issues:

1. What are the prominent factors constituting BE meta-cognition?

2. In what way(s) (if only) and/or to what extent meta-cognition affects competence-building of BE learners?

\section{Meta-Cognition: Categorization and Implication for BE Competence Building}

The experiment was conducted among 105 second-year BE majors of three natural classes in a university with two different teachers lecturing on International Trade Practice (in English), a compulsory subject for BE learners. International Trade Practice (in English) is considered highly practical and competence challenging, highlighting the comprehensive use of English in business contexts, such as international commodity quotation, 
transportation, insurance, and settlement. After a 16-week experiment, the candidates would be examined by statistically reliable papers composed of multiple choice questions, true or false statements, calculation questions, short questions, and case analysis. Judging from the results of previous examinations, the paper is reasonably structured, with moderate difficulty and high reliability and validity. Therefore, we consider the result an important indicator to assess competence-building for BE learners.

\section{Data Collection and Discussion}

Questionnaires and in-depth interviews are also very important research tools in this study. Drawing on previous studies of Flavell (1976) and Brown (1987), we self-designed a 13 items (see Table 2) with a Likert-5 scale to investigate the meta-cognitive dimensions and its impact on competence-building for BE learners.

Table 2

Items of the Questionnaire.

\begin{tabular}{|l|l|}
\hline No. & Item \\
\hline 1 & I am always planning well for BE courses and assignment. \\
\hline 2 & I often urge myself to complete the BE learning tasks conscientiously. \\
\hline 3 & I often self-evaluate the outcome of my learning tasks. \\
\hline 4 & I will reflect on myself when I fail to reach BE learning objectives. \\
\hline 5 & I can fully understand the BE tasks assigned by my teacher. \\
\hline 6 & I can fully grasp the knowledge and BE skills in classroom. \\
\hline 7 & I have consciously used BE expertise to carry out practical activities, with good results. \\
\hline 8 & I feel that my BE knowledge is still insufficient. I hope to work harder to improve myself. \\
\hline 9 & I feel that I lack knowledge in business of spoken and negotiating English. \\
\hline 10 & I often make up for weaknesses in BE studies by learning from strengths, and make every effort to improve myself. \\
\hline 11 & In BE class, I often participate in discussions and speak actively. \\
\hline 12 & I think both theory and practice are indispensable in BE learning. \\
\hline 13 & I like every experience of business activity and want to be a BE practitioner. \\
\hline
\end{tabular}

The questionnaire is divided into two parts:

1. Four multiple choice questions concerning the basic information of the subjects, that is, grade, specialty, and achievement;

2. Thirteen multiple choice questions of a Likert 5-level scale assigned: “ $5=$ points”, “ $4=$ points”, “ $3=$ points”, “2 = points”, and “1 = point”, respectively.

The survey results are carefully analyzed with the assistance of statistical software statistic package for social science (SPSS) 22.0 and analysis of moment structures (AMOS) 17.0 to quantitatively examine, the core dimension of $\mathrm{BE}$ meta-cognitive system and its impact on BE competence-building. A total of 105 questionnaires were sent out and 101 were collected, among which 91 were statistically valid, accounting for 90.1\% of the total. Questionnaire distribution and colleting procedures are performed strictly to ensure reliability of the results. With a Cronbach Alpha of 0.802, as suggested by Field (2005), it is highly reliable in statistics to do the research.

In order to scientifically construct the BE meta-cognitive system, we conducted an exploratory factor analysis with statistical software SPSS 22.0. Surprisingly, three prominent components (see Table 3) have been identified after principal component analysis and Kaiser Standardized Varimax Rotation (Kaiser-Meyer-Olkin $[\mathrm{KMO}]=0.703)$. It is worth noting that among the three factors, Factor 1 accounts for six of the majority items 
(items 11, 7, 13, 1, 2, and 3), while items 5, 4, 6, and 10 fall into the second category (Factor 2) and items 8, 9, and 12 are under the umbrella of Factor 3 . The exploratory factor analysis has born the following findings:

First of all, meta-cognitive experience, that is, the judgment and perception of BE activities and experiences, constitutes one of the main dimensions of BE meta-cognitive system, in which learners' judgment and perception of their own experience have an important impact on BE learning and competence-building. The majority of the respondents (77.9\%) hold that they "are often actively participating and speaking in classroom discussions" (Item 11). Ninety-five point six percent like the experiences of business activities and are determined to become BE practitioners in the future (Item 13), while $62.2 \%$ insist that well planning is vital for good BE experience (Item 1). Most importantly, 84.5\% believe that they "constantly urge themselves to complete the learning tasks conscientiously and are well-motivated to do that” (Item 2).

Secondly, the individual's planning, self-regulating, reflecting on, and evaluating of his/her own activities stand at the core of the meta-cognitive system. Seventy-six point six percent of the respondents will take the initiative to "self-reflect" when they fail to reach their goals (Item 4). With regard to learning outcomes, the self-assessment of vast majority (80.0\%) of the respondents claims that they could quickly grasp the knowledge and skills in class (Item 6). It is found that $94.4 \%$ of the participants passed the final (post-test), $46.7 \%$ of which achieved excellent results. Sixty-four point five percent of them are constantly learning from strengths to make up for their weaknesses, a vital strategy for self-improvement in BE learning. The study also found that the learner's regulation of his/her own activities (such as planning, reflecting, and evaluating) interface with all their cognitive experiences, such as feelings and judgments, and complement each other. There is no clear critical point that symbolizes the dividing of the two factors.

Thirdly, the learner's understanding of disciplinary knowledge, tasks, and themselves is also an important dimension of the BE meta-cognitive system. Ninety-five point four percent of the respondents hold that the disciplinary knowledge is "insufficient" (Item 8), and 94.4\% think that they are weak in "spoken English and negotiating skills" (Item 9). It is widely believed that "theory and practice are indispensable” (Item 12) in BE learning.

Table 3

Exploratory Factor Analysis

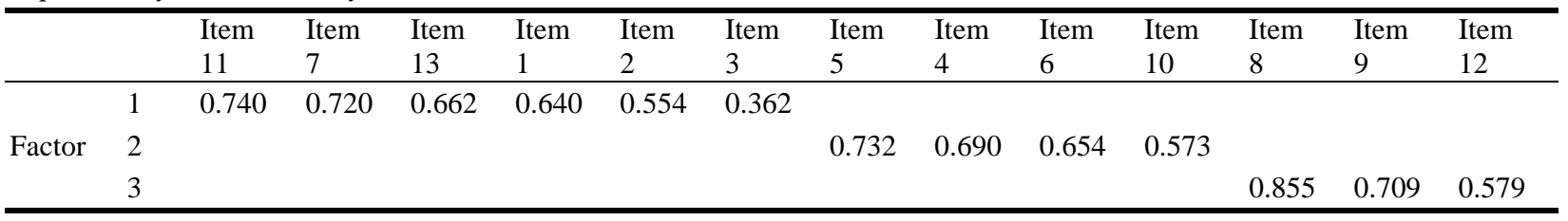

To sum up, meta-experience (feelings and judgment of self-experience), meta-regulation (planning, regulating, reflecting, and evaluating of self-activity), and meta-knowledge (knowledge on self, task, and knowledge) have been identified at the core of the cognitive meta-system, which interweave and complement each other across the macro-system of BE learners.

For the purpose of examining the typicality of the three factors, we conduct a confirmatory factor analysis (CFA) employing statistical tool AMOS 17.0. The results show that the main fitting indexes, such as goodness-of-fit index (GFI), adjusted goodness-of-fit index (AGFI), normed fit index (NFI), and Tucker Lewis index (TLI) are all greater than 0.9, while root mean square error of approximation (RMSEA) is less than 0.05, and minimum discrepancy per degree of freedom (CMIN/DF) is less than 2 (see Table 4), which represent a 
good fit. Therefore, it is safe to draw the conclusion that the above three factors are typical in the cognitive meta-system of BE learners, which constitute the main dimensions of BE competence system.

Table 4

Summary of CFA

\begin{tabular}{llllllllllll}
\hline Index & CMIN & $d f$ & $P$ & CMIN/DF & GFI & AGFI & RMSEA & NFI & IFI & TLI \\
\hline Model & 63.338 & 57 & 0.000 & 1.111 & 0.913 & 0.901 & 0.035 & 0.937 & 0.970 & 0.955 \\
\hline
\end{tabular}

\section{Categorization of BE Meta-Cognitive System}

In terms of quantitative research and factor analysis based categorization, we have reconstructed the meta-cognitive system (MATS) of BE learners (see Table 5) with regulatory factor dominating the central of the system, while meta-cognitive knowledge significantly influence learners' cognitive process by way of memories of varied meta-cognitive experiences.

Table 5

Categorization of BE Meta-Cognitive System

\begin{tabular}{|l|l|}
\hline Meta-cognition & Connotation \\
\hline Meta-cognitive regulation & Planning, regulating, reflecting, and evaluating of individual BE activities. \\
\hline Meta-cognitive knowledge & Knowledge on self, disciplinary knowledge, and tasks. \\
\hline Meta-cognitive experience & Feelings and judgment of individual experiences. \\
\hline
\end{tabular}

\section{Implication of MATS for BE Competence Building}

One-way analysis of covariance (ANOVA), a technique used to compare means of two or more samples, is a reliable way to examine the impact of MATS on BE competence-building. Consequently, taking the three groups of cognitive factors for independent variables, we conducted a one-way ANOVA of MATS, testing the impact of the independent variables on competence building and the dependent variable. The Levene's test (see Table 6) shows that the $p$-value 0.783 is much higher than 0.05 indicating that the variance is equal across groups, which satisfies the homogeneity condition of one-way ANOVA. It also evidences the validity of the following tests.

Table 6

Homogeneity of Variance Test

\begin{tabular}{llll}
\hline Levene's test & $d f 1$ & $d f 2$ & Sig. \\
\hline 0.245 & 2 & 87 & 0.783 \\
\hline
\end{tabular}

Table 7

Post Hoc-Scheffe

\begin{tabular}{|c|c|c|c|c|}
\hline \multirow{2}{*}{ Mean difference (I-J) } & \multirow{2}{*}{ Standard error } & \multirow{2}{*}{ Sig. } & \multicolumn{2}{|c|}{ 95\% confidence interval difference } \\
\hline & & & Lower & Upper \\
\hline-1.797 & 1.302 & 0.390 & -5.04 & 1.45 \\
\hline$-4.407^{*}$ & 1.314 & 0.005 & -7.68 & -1.14 \\
\hline 1.797 & 1.302 & 0.390 & -1.45 & 5.04 \\
\hline-2.610 & 1.324 & 0.149 & -5.91 & 0.69 \\
\hline $4.407^{*}$ & 1.314 & 0.005 & 1.14 & 7.68 \\
\hline 2.610 & 1.324 & 0.149 & -0.69 & 5.91 \\
\hline
\end{tabular}

Note. ${ }^{*}$. Significance level 0.05 . 
As different "lecturers" may impact competence building of BE learners from the three different classes, we conducted independent sample $t$-test and "post hoc multiple comparisons" to find out the extent to which lectures could influence the learners. It is found that the $p$-value between Class 2 (Lecturer A) and Class 3 (Lecturer B) is 0.390 , not statistically significant, while the $p$-value between Class 2 and Class 4 (Lecture $\mathrm{B}$ ) reaches 0.05 , a high significant level (see Table 7). It is surprising that there is no significant difference $(p=$ 0.149 ) in the probability of "meta-cognition" between Class 3 and Class 4 . Since the same lecturer has been shared by Class 3 and Class 4, it is assumed that the statistical difference between Class 2 and Class 4 should be a result of variety of learners, instead of lecturers.

In order to test the above assumption, we further divide the subjects into two groups based on the variable of "lecturer", and run an Independent samples t-test (see Table 8). The $p$-value of Levene's test $(p=0.323)$ is larger than 0.05 , which indicates that the variances are equal across the two groups. The significance probability of 2-tailed $t$-test, i.e., $p$-value is 0.009 , much smaller than 0.05 , and the $95 \%$ confidence interval does not contain 0 , which indicates that the means across groups is significant different. In other words, it is statistically evidenced that the meta-cognition across the two groups is significantly different.

Table 8

Independent Samples T-Test

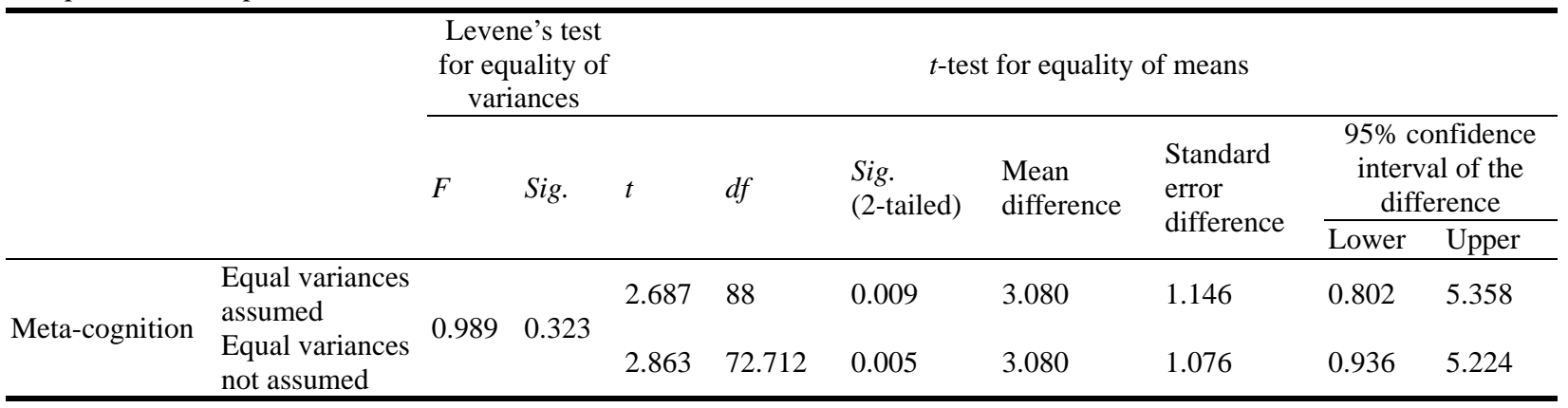

It is worth noting that the proficiency pre-test of the BE candidates reaches a $p$-value of .000 , closely correlated (correlation coefficient 0.519 ) with meta-cognition variable at 0.01 level (2-tailed). Therefore, we carried out ANCOVA and surprisingly found that the three groups share the same regression slopes, with a statistically insignificant $F$-value of 0.762 and $p$-value $(p=0.470)$ in the in-group interaction test. Considering the same regression slopes and variances, the following results (see Table 9) should be reliable to demonstrate the correlation of language proficiency with BE competence. As presented in Table 9, no significant impact of pre-competence has been found on the $\mathrm{BE}$ competence of the subjects, in that the $p$-value among different groups is 0.822 , much greater than 0.05 .

Table 9

Summary of ANCOVA

\begin{tabular}{lllcll}
\hline Source & Sum of squares & $d f$ & Mean square & $F$ & Sig. \\
\hline Contrast & $1,564.814$ & 21 & 74.515 & 0.693 & 0.822 \\
Error & $6,129.839$ & 57 & 107.541 & & \\
\hline
\end{tabular}

A finding has been born that neither the language proficiency nor different lectures that result in the competence difference in each individual. In order to find out the contributing factors, the three meta-cognitive factors have been carefully examined by means of one-way ANOVA. The results in Tables 10 and 11 show that 
meta-cognitive regulation (Factor 2) and meta-cognitive knowledge (Factor 3) are significantly influencing the level of post-test scores with respective $p$-values of 0.007 and 0.034 , less than 0.05 . More importantly, the stricter the learner's meta-cognitive regulation is, the stronger his/her BE competence would be. Good cognitive regulation significantly contributes to promoting return of human capitals, while little impact of meta-cognitive experience ( $p=0.963$ ) has been found on competence development. Therefore, enhancing meta-cognition of the individual, the meta-regulatory ability in particular, could be a good way to promote the value of human capitals in BE education.

Table 10

One-Way ANOVA (Factor 2)

\begin{tabular}{llllll}
\hline & Sum of squares & $d f$ & Mean square & $F$ & Sig. \\
\hline Between groups & $1,272.039$ & 10 & 127.204 & & \\
In groups & $3,611.917$ & 79 & 45.720 & 2.782 & 0.005 \\
Total & $4,883.956$ & 89 & & & \\
\hline
\end{tabular}

Table 11

One-Way ANOVA (Factor 3)

\begin{tabular}{lccccc}
\hline & Sum of squares & $d f$ & Mean square & $F$ & Sig. \\
\hline Between groups & 995.780 & 8 & 124.473 & & 0.014 \\
In groups & $3,888.175$ & 81 & 48.002 & 2.593 & \\
Total & $4,883.956$ & 89 & & & \\
\hline
\end{tabular}

\section{Conclusions}

Language in nature is a very important human capital endowed by language learners, characterized by economic attributes of "value", "utility”, and "cost”. Building on theories in cognitive linguistics and language economics, we propose that BE competence, as a human capital, is not only the unity of general cognition, but also the state of more complicated meta-cognitive activities. Since little literature addresses meta-cognitive issues in business context, the current research quantitatively focuses on the following two questions: First, what makes BE meta-cognition? Second, in what way (if only) and/or to what extent meta-cognition affects competence development of BE learners?

By doing statistical research and questionnaire-based categorization, this paper has constructed a systematic meta-cognition system for BE learners. With the regulatory factor standing in the core, two other meta-cognitive factors, i.e., meta-cognitive knowledge and meta-cognitive experience make the prototype of the learners' meta-cognitive system, characterized by learners' planning, regulating, reflecting, and evaluating of different BE activities, the understanding of self, interdisciplinary knowledge and tasks, judgments and feelings of various experiences. There is evidence showing that meta-cognitive regulation significantly impacts competence-building of BE learners. The stronger meta-regulation and more meta-knowledge are, the more competent BE learners would be. Therefore, meta-cognition cultivation could be an effective way to promote the value of human capitals in BE education.

\section{References}

Brown, A. L. (1987). Meta-cognition, executive control, self-regulation, and other more mysterious mechanisms. Hillsdale, NJ: Lawrence Erlbaum. 
Chang, L., \& Li, J. K. (2009). A study on the relevance of meta-cognitive strategies, listening comprehension and incidental vocabulary acquisition. Foreign Language World, (6), 50-57.

Chang, M., \& Yu, Y. L. (2014). An empirical study on improving postgraduate English online autonomous reading ability through meta-cognitive strategies. Foreign Language Research, (2), 111-114.

Chen, Q. S., \& Wen, Z. L. (2010). Meta-cognition and effective learning: Principles and conditions. Journal of East China Normal University (Educational Science), (1), 53-59.

Chen, X. X., \& Ge, S. L. (2016). A probe into procedural writing ability of Business English students from the perspective of business communication. Foreign Languages Research, (2), 58-62.

Field, A. (2005). Discovering statistics in using SPSS (2nd ed.). London: Sage.

Flavell, J. H. (1976). Meta-cognitive aspects of problem solving. In L. B. Resnick (Ed.), The nature of intelligence (p. 232). Hillsdale, NJ: Lawrence Erlbaum.

Flavell. J. H. (1979). Meta-cognition and cognitive monitoring: A new area of cognitive-developmental inquiry. American Psychologist, 34, 906-911.

He, B. B. (2017). Construction of systematic grammar competence for Business English based on categorization. Foreign Language and Literature, 33(1), 81-86.

Huang, M. (2012). Design and exploration of virtual learning environment for training students' meta-cognitive monitoring ability. The Chinese Journal of ICT in Education, (10), 48-51.

Ji, K. L. (2005). How to improve students' meta-cognitive knowledge: An experiment on teaching of English writing. Foreign Language Education, (2), 61-64.

Kisin, N. (2015). The relationship between meta-cognition and Business English learning. ELTA Journal, 3, 27-34.

Kong, W., \& Li, Q. H. (2008). A study of the relationship between meta-cognitive and cognitive strategies and L2 English proficiency. Modern Foreign Languages, 31(2), 173-184 \& 21.

Li, Q. H., \& Li, D. (2018). Exploring pragmatic ability model of Business English as a lingua franca. Foreign Language Research, (6), 74-81.

Liu, C. J. (2018). On the theoretical framework and cultivation approach of intercultural communicative competence for Business English majors. Foreign Language World, (3), 10-17.

Lu, W. J. (2006). The relationship between meta-cognitive strategies and English writing. Foreign Languages and Their Teaching, (9), 25-27 \& 39.

McKeown, R., \& Gentilucci, J. (2007). Think-aloud strategy: Meta-cognitive development and monitoring comprehension in the middle school second-language classroom. Journal of Adolescent \& Adult Literacy, 51, 2.

Mijuskovic, M. (2014). Meta-cognitive strategies. Pilogog, 5, 9.

Mu, D. F., \& Chen, Y. H. (2013). The regulative effect of cognitive flexibility on meta-cognitive monitoring and control. Psychological Development and Education, (2), 113-120.

Nie, A. Q., \& Xu, X. Q. (2001). Enlightenment to teaching of meta-cognition and cultivation of meta-cognition. Theory and Practice of Education, 21(11), 46-48.

O’Melley, J., \& Chamot, A. (1990). Learning strategies in second language acquisition. CUP: Cambridge University.

Oxford, R. (2003). Strategy inventory for language learning: What every teacher should know. New York: Newbury House Publisher.

Qu, L. L. (2014). A study on EFL reading strategies and meta-cognitive awareness through the think-aloud protocols. Foreign Language World, (4), 30-38.

Quirk, M. (2014). The meta-cognitive competency: The key to lifelong learning. In A., Kalet and C., Chou (Eds.), Remediation in medical education (pp. 223-234). New York: Springer.

Shao, S. Y., \& Zhao, R. (2011). Meta-cognitive strategies and autonomous learning ability-An investigation into self-access extensive reading. Technology Enhanced Foreign Language Education, (141), 60-64.

Shi, Q. (2012). Training meta-cognitive strategies of writing in college English comprehensive course. Journal of Southwest Minzu University (Humanities and Social Science), (s1), 244-246.

Stanciu, M., Dumitriub, C., Clipa, O., Ignat, A., Mâţă, L., \& Brezuleanu, C. (2011). Experimental research on meta-cognitive competence development at freshmen students from three Romanian universities. Prodedia-Social and Behavioural Sciences, 29, 1914-1923.

The Teaching Guiding Committee for College Foreign Language Majors Under the Ministry of Education. (2018). National Standard for teaching quality of undergraduate specialty in colleges and universities. Beijing: Higher Education Press. 
Wang, L., \& Fan, J. S. (2017). A review of foreign researches on competence scale for Business English majors. Journal of PLA University of Foreign Languages, 40(5), 102-109.

Wang, X. J. (2012). Meta-cognitive underpinnings of action research in light of “ $3+1$ ” paradigm. Technology Enhanced Foreign Language Education, (5), 44-49.

Wang, X. J. (2014). The correlation between autonomous learning motivation and meta-cognitive strategy for non-English majors. Foreign Language Education, 35(5), 72-75.

Wu, H. Y. (2006). An empirical study of meta-cognitive experience in College English writing. Foreign Languages and Their Teaching, (3), 28-30.

$\mathrm{Xu}, \mathrm{M} . \mathrm{Y}$. (2013). English listening teaching and meta-cognitive awareness training in normal colleges and universities. Education Review, (1), 117-119.

Yin, X. Y., \& Li, X. Z. (2015). Categorization of core competence of BE teachers and its implications. Journal of Guangdong University and Foreign Studies, 26(5), 108-112.

Zhang, L. (2009). Meta-cognitive awareness-An indispensable prerequisite for learner autonomy. Foreign Language World, (4), 56-60.

Zhang, Z. H., Feng, H. Y., Fu, Y. L., \& Wang, H. (2013). Mediation effect of listening strategies on the relationships between meta-cognitive awareness and listening performance. Foreign Language World, (5), 12-19 \&75.

Zhao, K. (2016). Enhancing meta-cognitive language learning strategy use and business language proficiency in technology-enhanced collaborative learning environment. International Journal of Computer-Assisted Language Learning and Teaching, 6(3), 68-78.

Zhao, L. P., \& Wang, W. G. (2013). An empirical study on meta-cognitive awareness of non-English majors in agricultural colleges. Journal of the Chinese Society of Education, (s1), 52-53 \& 59. 